\title{
PRINCÍPIOS DA CIRURGIA OCULAR
}

\author{
OCULAR SURGERY
}

Nivaldo Vieira de Souza

Docente do Departamento de Oftalmologia e Otorrinolaringologia da Faculdade de Medicina de Ribeirão Preto da Universidade de São Paulo. CORRESPONDÊNCIA: Nivaldo Vieira de Souza - Hospital das Clínicas - Departamento de Oftalmologia e Otorrinolaringologia - Campus Universitário - CEP: 14048-900 - Ribeirão Preto - SP. Fax: (016) 633-0186.

SOUZA NV de. Princípios da cirurgia ocular. Medicina, Ribeirão Preto, 30: 94-96, jan./mar. 1997.

RESUMO: Este capítulo aborda os aspectos comuns a todas as cirurgias oculares, dando ênfase aos cuidados pré e pós-operatórios dos pacientes oftalmológicos e às técnicas anestésicas empregadas.

UNITERMOS: Cirurgia Ocular. Anestesia.

\section{GENERALIDADES}

Conhecimentos das várias áreas, como Anatomia, Fisiologia e Patologia, são fundamentais para o exercício da cirurgia. Ao lado dessas áreas, que chamaremos básicas, o domínio da clínica cirúrgica, envolvendo os quadros clínicos, o diagnóstico diferencial e a etiopatogênese das doenças, nos permitirá fazer indicação da cirurgia com finalidade preventiva, curativa, estética, restauradora ou mista.

Assim, com conhecimentos básicos e de Clínica Cirúrgica, poderemos fazer uma indicação correta, tanto quanto à melhor técnica, como quando realizá-la, suas vantagens e, finalmente, chegar a inferências quanto ao prognóstico.

Lógicamente, tudo isso requer não só uma grande carga de conhecimentos prévios, como uma atualização constante. Cada vez mais, as operações oculares são microcirurgias, onde o emprego do microscópio e de material especial se tornaram fundamentais para a segurança e sucesso das mesmas.

\section{PREPARO DE PACIENTES}

A avaliação das condições sistêmicas do paciente é importante no preparo do mesmo, pois nos orientará tanto quanto ao tipo de anestesia e técnica cirúrgica a serem empregadas, como também, quanto aos cuidados pré e pós-operatórios. Devemos avaliar e controlar especialmente as condições do aparelho cardiovascular, funções hepática e renal e condições hematológicas, bem como colher informações dos antecedentes pessoais.

O uso de tranqüilizantes, no pré-operatório imediato, variará muito, de acordo com preferências do anestesista e, ou cirurgião.

O preparo ocular vai desde limpeza da pele com sabões bactericidas, tricotomia ciliar, midríase, uso de drogas hipotonizantes do olho (para as cirurgias em que se abre o olho), até uso de antibióticos tópicos por 24 ou 48 horas pré-operatoriamente (como preferem alguns cirurgiões).

\section{ANESTESIA}

Podemos utilizar tanto anestesia local como geral para, praticamente, todas as intervenções cirúrgicas oculares.

A anestesia geral tem sua indicação bem definida naqueles casos em que:

- não se tem cooperação do paciente (crianças, pacientes nervosos ou inquietos, etc.), ou não há comunicação com o paciente (surdos-mudos, pacientes que não coompreendem o idioma, etc.); 
- cirurgias longas (posição incômoda);

- cirurgias de instrução (permite demora e comunicação entre cirurgiões).

Nesse tipo de anestesia, devemos nos lembrar de alguns fatores que podem interferir no ato operatório, por exemplo, elevando a pressão ocular (a succinilcolina seria contra-indicada nas cirurgias em que se abre o olho), ou não imobilizando o globo ocular (o Inoval provoca nistagmo).

A anestesia local em Oftalmologia, empregada pela primeira vez em 1884, por Koller (Alemanha), sofreu evolução, sendo hoje, o método de escolha nos grandes centros oftalmológicos.

Ela pode ser tópica, através de instilação de colírio anestésico, que permite pequenas intervenções superficiais, como sutura de córnea ou conjuntiva, ou através de injeção subconjuntival, permitindo, além de suturas superficiais, a retirada de pterígio e tumores córneo-conjuntivais.

Nas cirurgias oculares mais extensas ou intra-oculares, a anestesia local usada é a injeção retrobulbar acompanhada da acinesia do músculo orbicular das pálpebras, ou a injeção peribulbar.

A anestesia retrobulbar é feita no ângulo temporal inferior da órbita, através da pele ou baixando-se a pálpebra inferior, através da conjuntiva, com agulha $40 \times 5$, injetando-se até $2,5 \mathrm{ml}$, dirigida, agora, bem inclinada, para o cone muscular. A peribulbar utiliza as mesmas vias, mas, com agulha de 40x6, injetamos até $15 \mathrm{ml}$ de anestésico na gordura periorbitária.

$\mathrm{O}$ agente anestésico, mais freqüentemente por nós empregado, é a lidocaína $2 \%$ com vasoconstrictor; às vezes, associamos a marcaína $0,75 \%$ com vasoconstrictor, que prolongará o tempo anestésico.

A paralisia do músculo orbicular da pálpebra pode ser necessária nas cirurgias oculares e a "céu aberto", para evitar a compressão do globo ocular e expulsão de seu conteúdo. É conseguida com a injeção de 5 a $10 \mathrm{ml}$ de lidocaína $2 \%$ com vasoconstrictor, no tronco do nervo facial, ao nível do côndilo da mandíbula, cerca de $1 \mathrm{~cm}$ para frente e abaixo do conduto auditivo externo (técnica de O'Brein) ou nos seus ramos temporofaciais, introduzindo-se a agulha, através da pálpebra, no ângulo orbitário ínfero-externo, junto ao periósteo, e dirigida para cima, paralela à borda orbitária, temporal, e, depois, horizontalmente, paralela à borda orbitária inferior (técnica VanLint).

A associação do anestésico com cerca de $200 \mathrm{U}$ de hialuronidase irá permitir a ampla difusão do líqüido e perfeita anestesia do olho, associada à paresia dos músculos extra-oculares e palpebrais (não havendo, portanto, necessidade de acinesia do nervo facial).
A anestesia mista (local + sedação), preferida por alguns, é contra-indicada por nós, uma vez que a sedação deixa o paciente sonolento e semi-inconsciente o que faz com que ele, eventualmente, se agite ou assuste, tornando-se pouco cooperativo durante o ato operatório.

\section{ATO OPERATÓRIO}

A descrição das cirurgias propriamente ditas, foge ao objetivo da graduação. Vamos nos ater aos passos comuns, praticamente, a todas as cirurgias oculares.

A posição do paciente na mesa operatória é sempre de decúbito dorsal (raramente adotando-se outra posição). O cirurgião opera sentado, à cabeceira, e tem apoio para os braços.

A assepsia da pele é feita centrifugamente, utilizando qualquer agente, de preferência colorido, para melhor definição da área asséptica.

Após exposição do olho com aparelhos especiais (blefarostatos), ou com fios, através das bordas palpebrais, ancorados no campo cirúrgico, faz-se a lavagem abundante dos fundos de saco conjuntivais com soro fisiológico e cotonetes.

A apresentação do campo operatório exige o posicionamento do olho, conforme a cirurgia a ser executada, e, para tanto, utilizamos a fixação de um ou mais músculos extra-oculares com fio de seda ou algodão 4-0.

Usa-se abrir a conjuntiva fora da área da esclera, onde se atuará (em casos de cirurgia intra-ocular) formando, assim, um retalho conjuntival que protegerá a ferida operatória.

O material de sutura empregado é o mais variado possível, mas, de modo geral, é sempre o fio mais fino e agulha mais atraumática possível.

Assim, para o fechamento da conjuntiva, podemos usar fios absorvíveis sintéticos (poliglactina -vicryl 6-0 ou 7-0), ou orgânicos (colágeno - catgut 6-0), ou fios não absorvíveis, (seda 6-0, poliester 6-0, etc.). Nas suturas de córnea, utilizamos os mais finos fios existentes, para se ter a menor lesão cicatricial possível, uma vez que a transparência da mesma é fundamental, como seda 8-0, monofilamento de nylon 9-0 ou 10-0, etc., ou absorvíveis como poliglactina (vicryl 8-0), seda-virgem 9-0, etc. No fechamento da esclera, nós, particularmente, recomendamos fios não-absorvíveis, uma vez que a cicatrização deste tecido é muito lenta.

Para sutura dos músculos, usamos material de absorção lenta, como colágeno cromado (catgut cromado 6-0), ou não absorvíveis (fios sintéticos não-trançados 6-0 ou 7-0). 
Os tecidos intra-oculares, à exceção da íris, não podem ser suturados e, no caso de sua ruptura, por exemplo, nos traumas perfurantes do globo ocular, com lesão dessas estruturas (úvea e retina) a conduta deve ser, além da sutura do tecido externo (córnea ou esclera), aplicação de coagulação no local perfurado, utilizando a corrente elétrica (diatermia), baixa temperatura (criocoagulação) ou luz (fotocoagulação).

\section{PÓS-OPERATÓRIO}

Os cuidados pós-operatórios, em Oftalmologia, não são tão intensos como em outras especialidades, consistindo praticamente no repouso ocular.

No caso de cirurgia superficial do olho, esta pode ser considerada como ambulatorial. Nas intra-oculares, os cuidados consistem no repouso, com o olho operado ocluído, e uso de protetor especial, ou, como fazemos rotineiramente, com um cone de celulóide.

Medicações antiemética e laxante, às vezes, se fazem necessárias, para evitar a compressão reflexa do globo ocular.

Como, geralmente, nossos pacientes são idosos (a maior porcentagem de cirurgias é da catarata senil) a deambulação deve ser a mais precoce possível, para se evitarem problemas cardiopulmonares.

Os curativos devem ser trocados diariamente, pois o calor e a baixa umidade do ar de nossa região deixam seco o olho ocluído, portanto, irritado e dolorido.

Quando se implanta lente intra-ocular (LIO) há menor desarranjo e maior proteção das estruturas intra-oculares, o que permitirá a deambulação precoce do paciente, na maioria dos casos, suprimindo a necessidade de internação, e permitindo a desoclusão do olho, geralmente, em 24 horas.

Raramente usamos antibióticos ou antiinflamatórios sistêmicos, em nossas cirurgias de rotina.

\section{CIRURGIAS OCULARES MAIS FREQÜENTES}

A - Facectomia: é a retirada da catarata. Para tanto, abre-se o olho até $180^{\circ}$, no limbo superior, após abertura da conjuntiva na mesma extensão, um pouco para atrás do limbo (retalho base-límbica) ou abertura de conjuntiva no limbo (retalho base-fórnice). Retira-se o cristalino, utilizando-se um crioextrator (extração intracapsular) ou rasga-se a cápsula anterior e retira-se o núcleo e o córtex, deixando a cápsula posterior (extração extracapsular). A segunda técnica é a mais utilizada, atualmente, devido ao implante de lente substituída do cristalino (pseudofacia).

B - Retinopexia: o princípio desta cirurgia é selar o rasgão retiniano, que leva ao descolamento da retina, e fazer com que a retina permaneça fortemente aderida ao epitélio pigmentar. Para tanto, faz-se a introflexão da esclera, na região do rasgão, e produz-se uma reação inflamatória no local. Pode-se puncionar o líquido sub-retiniano que se produz sob a retina descolada.

C - Antiglaucomatosa: tem por finalidade abrir via de drenagem para o humor aquoso, para o espaço subconjuntival (de onde passará à corrente sangüínea). Para tanto, faz-se uma abertura na esclera, próxima ao limbo, em direção à câmara anterior, após abertura da conjuntiva, o mais longe possível da ferida da esclera, onde se formará uma bolha de aquoso. Após a abertura, pode-se adotar uma das diversas técnicas existentes, mas o procedimento mais utilizado é a retirada de um fragmento do trabeculado (trabeculectomia).

D - Correção de estrabismo: baseia-se no reforço ou enfraquecimento dos músculos extra-oculares. No reforço, é feito um encurtamento da bainha do músculo e, no enfraquecimento, uma reinserção mais posterior do músculo comprometido.

E - Transplante de córnea: pode ter a finalidade óptica, para recuperação da visão, ou terapêutica, nos casos de úlceras infectadas ou perda de substância corneana.

F - Cirurgias refrativas: o objetivo destas cirurgias é a correção dos vícios de refração, através de mudança na curvatura de superfície anterior da córnea.

G - Vitrectomia: consiste na retirada do corpo vítreo opacificado ou membranas fibrovasculares no vítreo, utilizando-se aparelhos especiais, que fazem irrigação, aspiração e corte das estruturas no vítreo.

SOUZA NV de. Ocular surgery. Medicina, Ribeirão Preto, 30: 94-96, jan./march 1997.

ABSTRACT: The author comments about the main aspects of ocular surgery, with emphasis in the patient care and the anesthesic techniques.

UNITERMS: Surgery, Eye. Anesthesia. 